\title{
Experimental study of the VFD's speed stabilization efficiency under torque disturbances
}

\author{
Vladimir L. Kodkin, Aleksandr S. Anikin
}

Departement of Theoretical fundamentals of electrical engineering, South Ural State University, Chelyabinsk, Russia

\begin{tabular}{l} 
Article Info \\
\hline Article history: \\
Received Jul 31, 2020 \\
Revised Jan 12, 2021 \\
Accepted Feb 2, 2021 \\
\hline
\end{tabular}

\section{Keywords:}

Load disturbance

Positive feedback

Scalar control

Stabilization efficiency

Variable frequency drive

Vector control

\section{Corresponding Author:}

Aleksandr S. Anikin

Departement of Theoretical fundamentals of electrical engineering

South Ural State University

76, Lenin prospekt, Chelyabinsk, Russia. 454080

Email: anikinas@susu.ru

\begin{abstract}
The article presents a technique for experimental research of variable frequency drives experiencing periodic torque disturbances of variable frequency. The technique is based on the nonlinear transfer function of a link of an asynchronous electric motor, which forms an electromagnetic torque, proposed in previously published articles. The dependence of the transfer function on the frequency of the stator voltage and slip determines the research methodology. Experiments have shown the advantage of the dynamic characteristics of a drive with a positive feedback on the stator current over electric drives with traditional control methods (vector and scalar sensorless), and in terms of dynamic characteristics they also exceed drives with a vector control closed in motor speed. These advantages are retained when the frequency of change of the disturbing torque is changed from 0 to $5 \mathrm{~Hz}$.
\end{abstract}

This is an open access article under the CC BY-SA license.

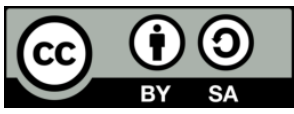

\section{INTRODUCTION}

One of the important tasks of modern variable frequency drives (VFD) is to maintain the value of the controlled coordinate at the level of the reference signal under various disturbances [1]-[4]. For an electric drive operating in the mode of maintaining a given speed of rotation of the shaft, the most important and complex mode is surges and variations of torque disturbances. To fend off these indignations, i.e. keeping the rotation speed at the required level is quite difficult. There are many reasons for this, but the most significant are the following.

1) The natural rigidity of the mechanical characteristics of an asynchronous electric motor is not enough. So, the rated load torque leads to a decrease in speed by 4-10\% [5]-[7] in relation to the idle speed. For most high-tech mechanisms, the tolerance does not exceed $1 \%$.

2) Torque disturbances are parried due to the external velocity loop, i.e. after the moment of loading, there should be an initial dynamic dip of $10-15 \%$. This dip is practically not regulated by the tuning of the PID controllers incorporated in the control systems of asynchronous electric drives with frequency control, i.e. changing the parameters of the frequency converter [8].

3) In VFD with vector control with speed feedback the existing limitation of the ratio of the amplitude of the stator voltage to its frequency (U/f) limits the magnetic flux and increases the speed recovery time to $1 \mathrm{~s}$ [8]-[12]. With modern technological requirements, this is a very high value, which sharply increases the likelihood of a significant violation of the required operating mode of the drive and the unit as a whole. 
4) The process of load parry is complicated by the fact that the power elements of the drive (frequency converter, electric motor and gearbox) have a significant number of nonlinear elements [13]-[17]. The presence in the real mechanism of gaps, backlash, changing in the process of wear of elements, leads to time delays, which cannot be completely eliminated by complicating the automatic control system.

5) In standard frequency converters from leading world manufacturers, for speed stabilization modes, a vector control mode is provided, which has a number of significant drawbacks, which will be indicated below.

In standard frequency converters of leading world manufacturers for speed stabilization modes, a vector control mode is provided, which has a number of significant drawbacks that reduce efficiency precisely in the mode of parrying external moment disturbances, which will be discussed below. These and other complexities of the process of parrying moment loads make it difficult for engineers to choose effective control systems for electric drives, limiting themselves to the choice of vector control schemes, which are considered to be the best option for VFD.

Vector equations, which traditionally describe VFD, do not allow effective application of theoretical (computational) methods for identifying dynamic characteristics of electric drives proposed in [18]-[20]. Well proven in the analysis of the dynamics of DC drives, these methods will require significant linearization of the generalized equations of induction motors and the result of such calculations can differ significantly from practice, from real dynamic processes in drives with frequency control. Therefore, the studies, the results of which are presented in this article, relied primarily on experiments. For this, asynchronous electric motors controlled by ATV frequency converters of the "Schneider-Electric" company, included in the laboratory stand, were used.

\section{PROBLEM DEFINITION}

In works [21], [22] the results of experimental research and mathematical modeling of load surges in asynchronous electric drives with frequency control are given. Let's note the most important ones.

1) The processes of load parry in a drive with vector control Figure 1 have practically no advantage over processes with scalar control Figure 2.

2) A vector control drive, closed in speed, has zero static, but large dynamic errors and a long-term speed recovery process Figure 3.

3) A drive with dynamic positive stator current feedback has better speed stabilization and load parity. Figure 4. The functioning of such control is described in detail in work [23]. This drive is described in detail in the works of the authors [21], [24].

4) These comparative results are completely confirmed by experiments carried out with a drive in which the rotor current was controlled [8], [24].

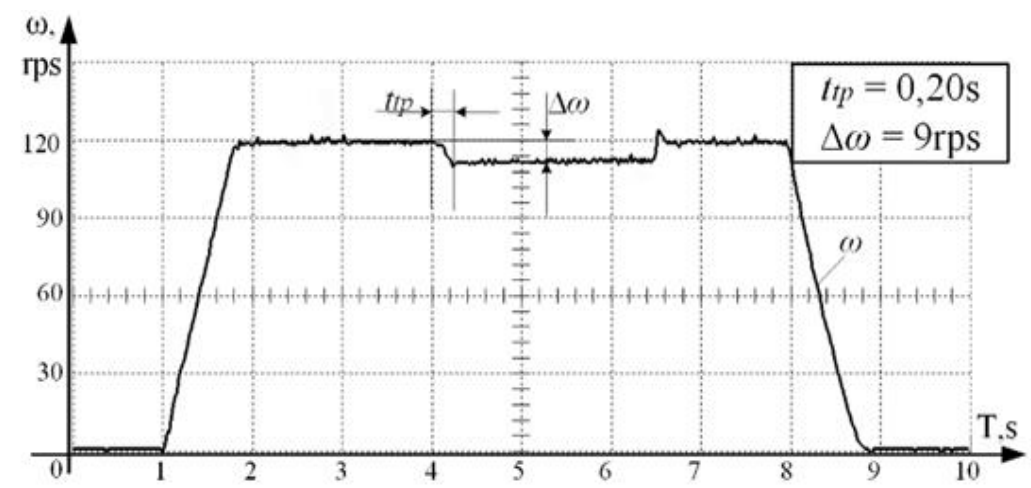

Figure 1. Transient of VFD with sensorless vector control 


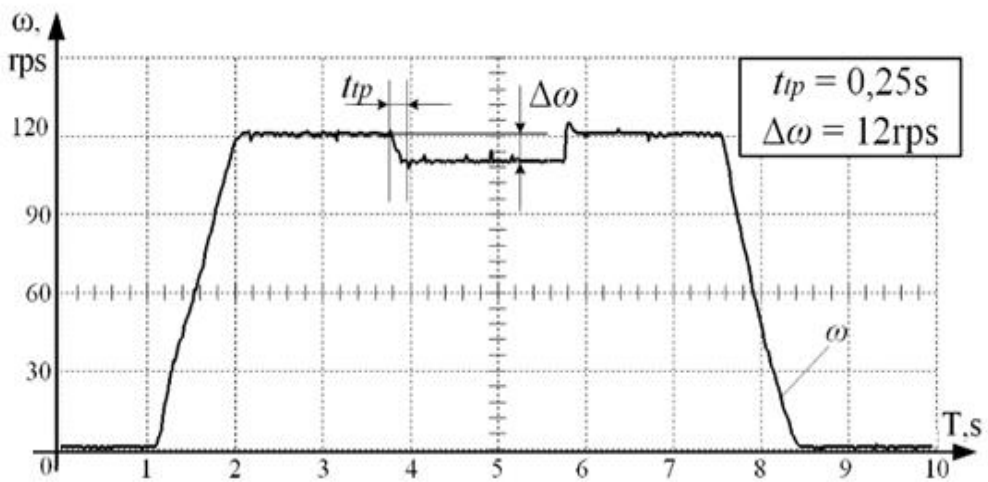

Figure 2 Transient of VFD with scalar control

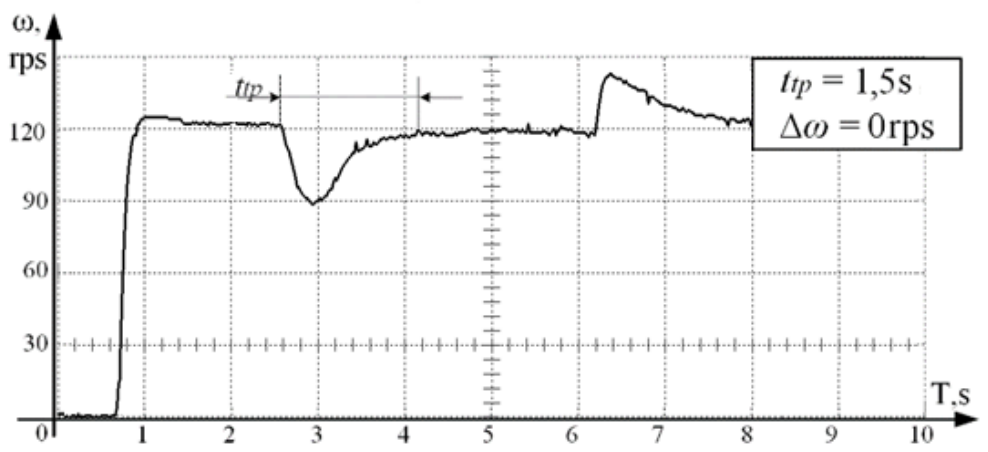

Figure 3. Transient of VFD with vector control with speed feedback

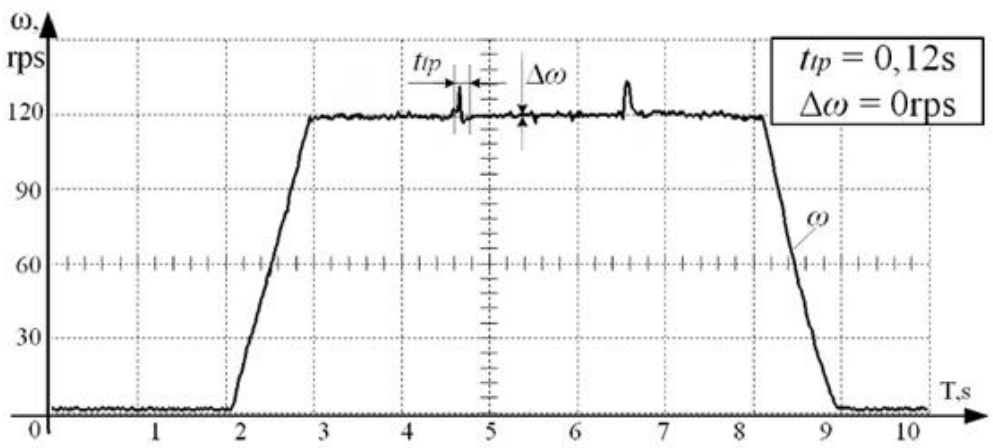

Figure 4. Transient of VFD with scalar control with DPF

Explanations of these results are given in [25]. For this, a nonlinear transfer function of the asynchronous motor links was proposed, taking into account the frequency of the static voltage and the load through the magnitude of the absolute slip

$$
W(p)=\frac{2 M_{k}\left(T_{2}^{\prime} p+1\right) S_{k}}{\omega_{1}\left[\left(1+T_{2}^{\prime} p\right)^{2} S_{k}^{2}+\beta^{2}\right]}
$$

Where, $T_{2}^{\prime}=\frac{L_{k}}{R_{2}}-$ the transient time constant of the rotor, $\beta=\frac{\omega}{\omega_{1}}-$ the relative slip, $M_{k}-$ the critical moment, $s_{k}-$ the critical slip at the nominal frequency $\omega_{1}$ 
The block diagram of the motor with this link is shown in Figure 5. As follows from formula (1) and Figure 5, when the load rises, the structure of the transfer function changes. From the first-order link at $\beta=0$, the transfer function becomes the transfer function of the second-order vibrational link

$$
W_{\mathrm{D}}(p)=\frac{m}{\Delta \omega}=\frac{2 M_{k}}{\left(1+T_{2} \prime p\right) S_{k} \omega_{1}}
$$

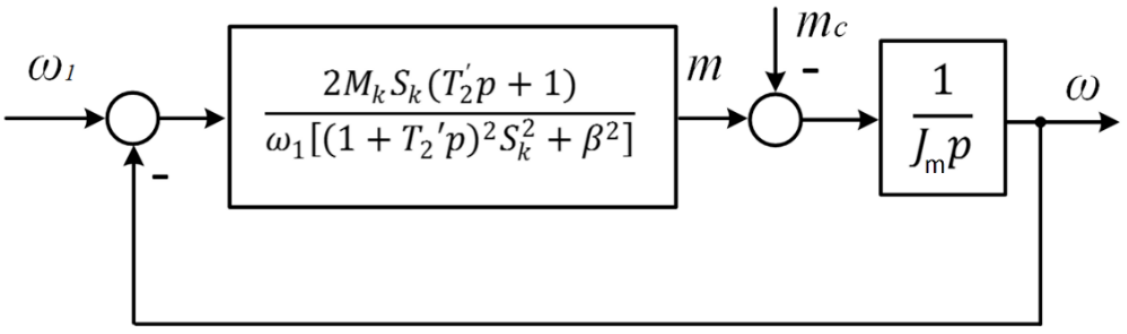

Figure 5 Structural diagram of an asynchronous motor in the working area

Figure 6 shows the frequency characteristics of the link of the formation of the electromagnetic torque at $\beta=0$, which corresponds to idle operation, and at $\beta=10 \%$, which corresponds to a load close to the nominal. The differences in performance are very significant. It is very difficult to theoretically assess the quality of the transition process with such a change. The control algorithm selected in the frequency converter changes the amplitude and frequency of the stator voltage. In formula (1), these changes "appear" as changes in frequency and values of $\mathrm{M}_{\mathrm{k}}$ and $\mathrm{S}_{\mathrm{k}}$. To what extent these changes are effective, we can judge by the processes of speed change during load surges, the authors do not know the exact engineering methods, therefore, to solve the problem of identifying the dynamics of an electric drive by the input of a torque load, an experimental method based on the transfer function (1) is proposed.

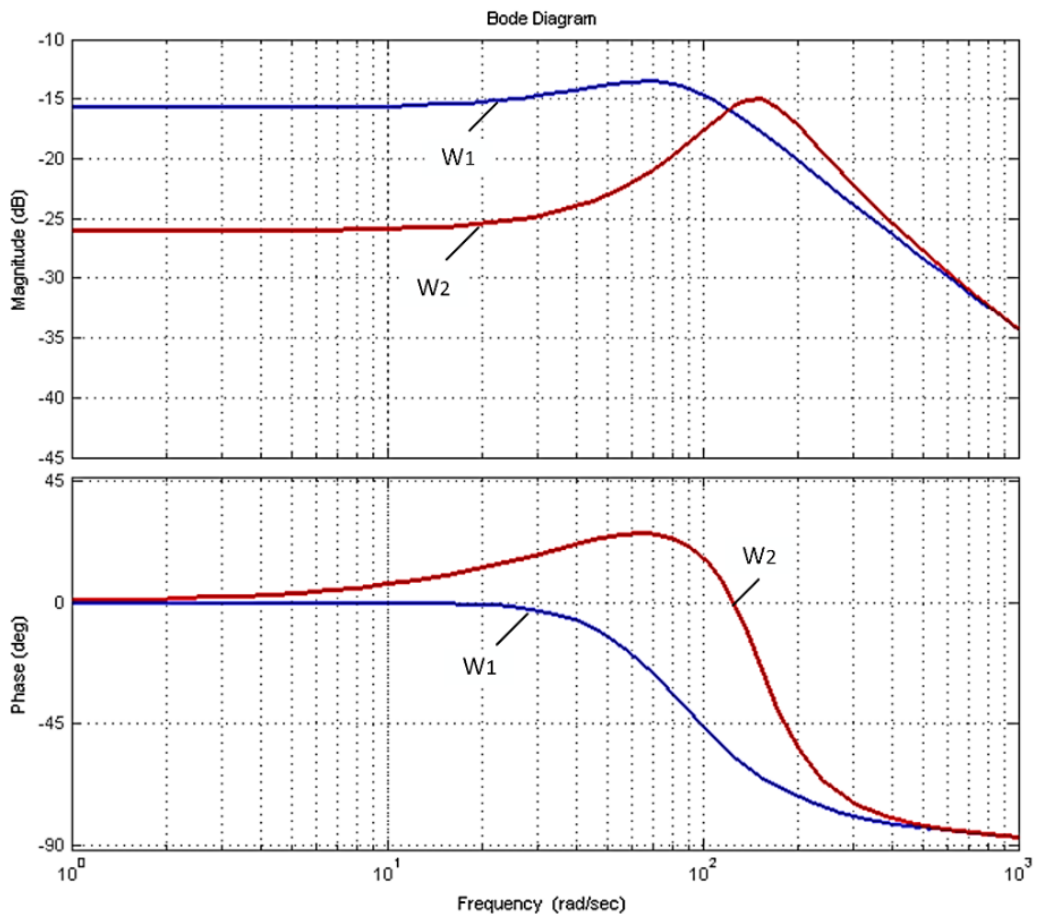

Figure 6. Frequency responses of an electric motor at a stator voltage frequency of $10 \mathrm{~Hz}$ and slip, corresponding to low (W1) and nominal (W2) loads 
Because the transfer function changes when the stator voltage frequency changes. $\omega 1$, it is necessary to conduct a series of experiments at each "significant" frequency of the stator voltage. Since the dynamics of the drive, like any automatic control system, can be determined by its linearized frequency response, it is necessary to obtain the processes of speed change during load surges. Changing according to the harmonic law with a certain frequency. For a more detailed study of these frequencies, there should be several from the investigated frequency range. Frequencies and amplitudes of disturbances should be selected as the most probable disturbances for a given electric drive and the mechanism as a whole. This range of values is determined as a result of studies of the mechanism with which the electric drive is supposed to work.

Also, as a result of research, the most probable constant engine speed should be selected. Determined by the frequency of the stator voltage. This makes the verification by this method rather laborious and cumbersome. But for nonlinear systems, this is the only true and accurate method. In a nonlinear system, it is impossible to transfer the experimental results obtained in any specific conditions - for example, parrying a "stepwise" load surge at the rated speed of rotation, to transfer to the processes of load surges at other speeds. Also, parrying a surge of a static load does not allow predicting the parameters of the processes of parrying a variable load, even with a sufficiently low frequency of change.

Virtually any form of load torque variation can be selected for proof testing. Since most periodic functions are fairly accurately represented by the sum of harmonics of different frequencies, harmonic functions of the load torque change can be considered preferable. However, the technique can also be effective for other functions of changing the load moment, if studies of the mechanism or complex determine these functions. Comparison of the parameters of the processes of the speed of rotation and the given disturbing influences will show the efficiency of torque disturbances parry by one or another VFD's control algorithm.

\section{EXPERIMENTAL RESEARCH}

The experiments were carried out on the stand shown in Figure 7. The experiments were carried out as follows. The investigated VFD was accelerated to a given speed corresponding to the frequency of the stator voltage from 10 to $50 \mathrm{~Hz}$, for example, to $10 \mathrm{~Hz}, 20 \mathrm{~Hz}, 30 \mathrm{~Hz}, 40 \mathrm{~Hz}$ and $50 \mathrm{~Hz}$. In accordance with the interpretation of the formula, the frequency properties of the drive must be controlled at several, the most probable speeds of rotation, supplying the disturbing moments with a value that does not significantly change the transfer function defined by this formula. This method will allow the most objective comparison of the effectiveness of various AED control methods.

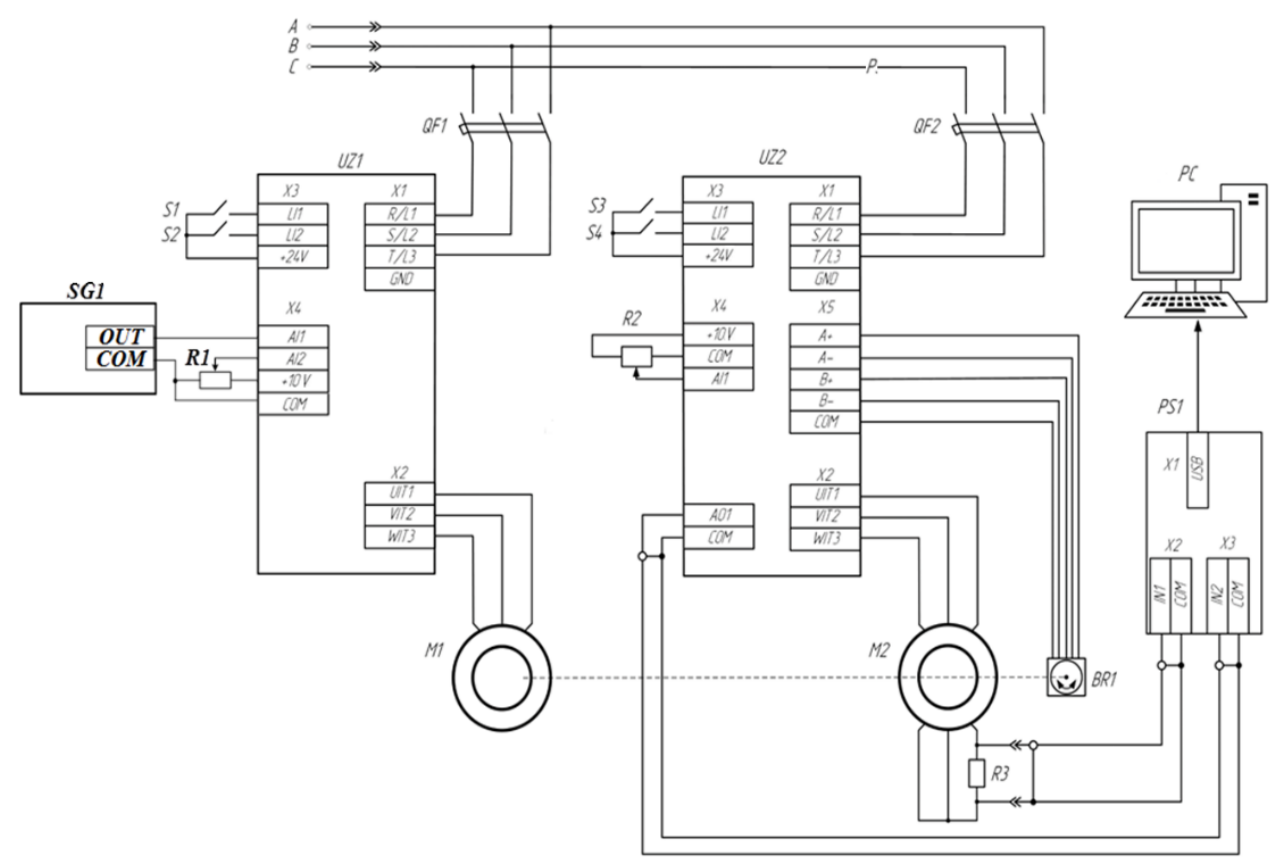

Figure 7 The stand electrical scheme SG1- signal generator; UZ1, UZ2-frequency converter; BR-encoder; PC-personal computer; PS1-oscilloscope; M1-load motor; M2-slip-ring induction motor 
The investigated VFD was accelerated to a given speed corresponding to the frequency of the stator voltage from 10 to $50 \mathrm{~Hz}$, for example, to $10 \mathrm{~Hz}, 20 \mathrm{~Hz}, 30 \mathrm{~Hz}, 40 \mathrm{~Hz}$ and $50 \mathrm{~Hz}$. A harmonic signal with a frequency of 0 to $5 \mathrm{~Hz}$ is applied to the load drive, and an amplitude that slightly changes the transfer function in parameter $\beta$. For each of the experiments, the processes in the speed of rotation of the motor shaft are recorded. From a signal that is a sinusoid of the same frequency, as the input harmonic signal for the torque of the load drive, the amplitude of the uncompensated fluctuation of the speed and the phase shift between the signal of the reference and the sinusoid of the speed are distinguished.

The greater the amplitude of the speed fluctuation and the phase shift between the reference and the speed signal, the worse the drive's ability to stabilize speed under complex torque disturbances. An example for a frequency of $1 \mathrm{~Hz}$ is shown in Figure 8. The reference signal Figure 8 (d) forms a sinusoidal disturbing torque on the load motor. The reactions of VFD with different control systems to this disturbance are shown in Figure 8(a), 8(b) and 8(c).

\section{ANALYSIS OF EXPERIMENTAL RESULTS}

From these diagrams Figure 8 it follows that VFDs with "traditional" sensorless controls (vector and scalar) have practically the same stabilization characteristics under torque disturbances. An electric drive with dynamic positive feedback on the stator current (DPF), in which, as shown by numerous studies [19], a constant magnetic flux of the rotor is formed, have the best characteristics under periodic torque disturbances.

Vector control with speed feedback in this mode is ineffective. There are many reasons for this, we note the main ones:

1. All frequency converters limit the stator flux in all modes (U/f ratio).

2. The initial assumption about the harmonic nature of currents in asynchronous motors is very far from the truth. This is shown in [22], [24]. The effect of this assumption on the torque and speed of the motor is theoretically very difficult to calculate, but it can be significant.

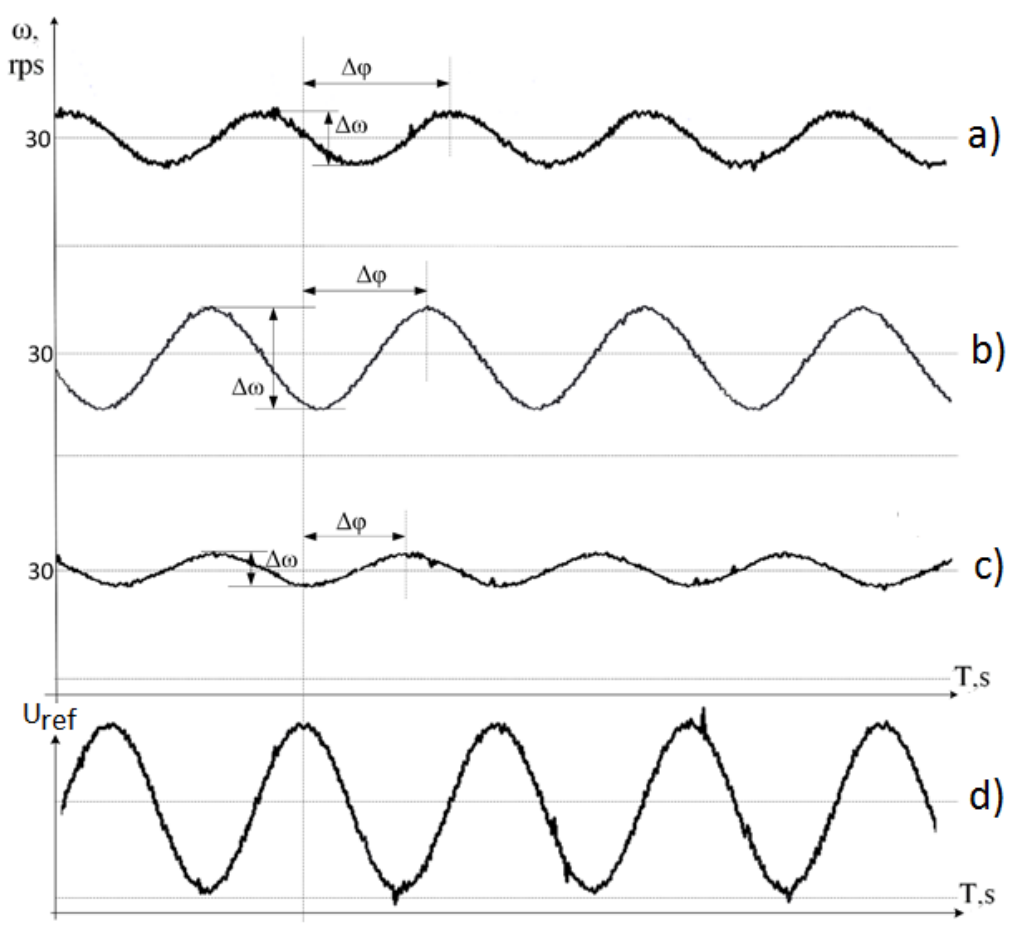

Figure 8. Diagrams of VFD under sinusoidal disturbing torque with a frequency of $1 \mathrm{~Hz}$ (a) Open loop system (scalar and vector control), (b) vector control with speed feedback, (c) Scalar control with DPF, (d) speed reference signal

These reasons are well known to engineers, we suggest paying attention to the following. When developing a vector control algorithm, in addition to using a mathematical model of the motor, the 
parameters of which always differ from the real motor, the assumption of sinusoidal currents is taken. This is necessary to eliminate cross-links, and therefore to increase the controllability of the system. At the same time, the connections that provide the natural mechanical characteristic of the induction motor are also eliminated, and the entire function of parrying disturbing influences falls on the speed controller. Under static load, this leads to a delay in the speed recovery process. With a harmonic disturbing torque, starting with a frequency of $1 \mathrm{~Hz}$ and higher, the vector control drive, closed in speed, cannot fend off the load Figure 8 (c).

Attention should be paid to the convenience of the proposed method of experimental identification of the stabilizing capabilities of the drive. Since the torque reference signal is the same in all experiments, there is no need to calculate the exact values of the frequency characteristics of the drive under test. It is enough to compare the absolute values of the amplitudes and phase shift of the speed signal.

So, in the experiment at a frequency of $1 \mathrm{~Hz}$, the amplitude of the "remaining" sinusoidal speed signal was $1.19 \mathrm{rad} / \mathrm{s}$, and in an electric drive, closed in speed, the amplitude of a similar change in speed is $3.31 \mathrm{rad} / \mathrm{s}$. That is, the speed stabilization in an electric drive with DPF in relation to the torque perturbations is 3 times better than in a vector control drive with a speed feedback (Table 1). Open-loop drives Figure 8(a) that parry the load only due to "natural" stabilization have an error amplitude of $2 \mathrm{rad} / \mathrm{s}$.

Table 1. Experimental results of VFD under sinusoidal disturbing torque with a frequency of $1 \mathrm{~Hz}$

\begin{tabular}{ccc}
\hline Control system type & $\Delta \omega, \mathrm{rad} / \mathrm{s}$ & $\Delta \varphi$, el. Deg \\
\hline Open loop system & $\pm 2,19$ & 270 \\
Speed feedback system & $\pm 3,31$ & 230 \\
Current feedback system & $\pm 1,19$ & 200 \\
\hline
\end{tabular}

The data for the experiment at a stator voltage frequency of $30 \mathrm{~Hz}$ at a harmonic disturbing signal frequency of $1 \mathrm{~Hz}$ are given in Table 1 . The rest of the results in the disturbance frequency range up to $5 \mathrm{~Hz}$ and stator voltage frequencies from 10 to $50 \mathrm{~Hz}$ are similar.

\section{CONCLUSIONS}

From the results of experiments, it follows that a structure with a positive dynamic feedback on the stator current of an asynchronous electric motor largely linearizes an asynchronous electric drive with frequency control and a nonlinear transfer function of the link that forms the electromagnetic torque. The advantages of VFD with such a coupling were evident in all experiments.

Attention should be paid to the lowest efficiency of the speed feedback vector control drive. Under a static load, its algorithm leads to a delay in the speed recovery process. With a harmonic disturbing torque starting from a frequency of $1 \mathrm{~Hz}$ and higher, the drive cannot counter the load Figure 8.

The method of identifying the dynamics of the drive by the torque input is effective, has a high "sensitivity" and is able to solve the original problem of choosing the most effective control algorithm depending on the nature of the change in the load torque.

The formula of the nonlinear transfer function of the torque generation link in an asynchronous electric motor is sufficiently accurate for engineering calculations and efficiency improvement methods for the range of stator voltage frequency variation from 0 to $50 \mathrm{~Hz}$.

VFD with positive dynamic feedback on the stator current has the best ability to suppress variable moment disturbances of low frequencies (from 0 to $5 \mathrm{~Hz}$ ) in comparison with standard control algorithms scalar and vector.

\section{REFERENCES}

[1] De Doncker, Duco W.J. Pulle, Andre Veltman, "Advanced Electrical Drives: Analysis, Modeling, Control," Springer, pp. 474, 2011.

[2] Pro Literatur Verlag, "Cubero Sam (ed.) Industrial Robotics. Theory, Modelling and Control," pp. 952, 2007.

[3] N. A. Sukhenko, G. Ya. Pyatibratov, A. A. Danshina, L. L. Altunyan, "Prospective Electromechanical Control Systems of Industrial Manipulator Efforts," International Journal of Power Electronics and Drive System (IJPEDS), vol. 7, no. 2, pp. 416-421, 2016. http://doi.org/10.11591/ijpeds.v7.i2.pp416-421

[4] Ferreira, F.J.T.E.,De Almeida, A.T., "Overview on energy saving opportunities in electric motor driven systems Part 1: System efficiency improvement," 52nd IEEE/IAS Industrial and Commercial Power Systems Technical Conference, I and CPS, 2016. DOI: 10.1109/ICPS.2016.7490219

[5] Ilyina A.G., Usoltsev A.A., "Optimal motion control during positioning and its modeling in the MathLab Simulink environment," Izvestiya VUZov. Instrument making, vol. 51, no. 6, pp. 63-68, 2008. 
[6] Chiasson John, "Modeling And High Performance Control Of Electric Machines," John Wiley \& Sons, Inc., pp. 7092005

[7] Usoltsev A. A., "Determination of the parameters of the asynchronous motor model according to the reference data," News of universities. Instrument making, vol. 51, no. 10, pp. 35-41, 2008.

[8] V.L. Kodkin, A.S. Anikin, A.A. Baldenkov "The analysis of the quality of the frequency control of induction motor carried out on the basis of the processes in the rotor circuit" XI International Scientific and Technical Conference Dynamics of Systems, Mechanisms and Machines Proceedings 2017. Omsk, pp. 14-16, 2017. https://doi.org/10.1088/1742-6596/944/1/012052

[9] Mishchenko V.A., "The vector control method of electromechanical converters," Electrical Engineering, no. 7. pp.47-51, 2004.

[10] Shevchenko, A.F. and Abdel' Maksud Selim, S.A., "Vector control of stator's current in synchronous motor with permanent magnets for drowned pump drive," Nauchn. Vestn. Novosib. Gos. Tekhn. Univ, vol. 2, no. 43, 2011.

[11] Marc Perron; Hoang Le-Huy, "Full Load Range Neural Network Efficiency Optimization of an Induction Motor with Vector Control using Discontinuous PWM," Marc Perron; Hoang Le-Huy, 2006 IEEE International Symposium on Industrial Electronics. https://ieeexplore.ieee.org/document/4077917

[12] Srinivas Gangishetti, Tarakalyani Sandipamu, "Different Control Schemes for Sensor Less Vector Control of Induction Motor," International Journal of Power Electronics and Drive System (IJPEDS), vol. 8, no. 2, pp. 712-721, 2017.

[13] Figaro B.I. Pavlyachik L.B., "Regulating electrical drives of alternating-current.-Misnk," Technoperspectiva, pp. 363, 2006

[14] Gun V.S., Bakin A.A., Litvinova E.V., "Analysis of the dynamic properties of the discrete control of the regulation by the linear approximation of difference equations," Science SUSU: proceedings of the 70th scientific conference. Technical Science Section 2017.

[15] Goun, V.S., Anikin, A.S. \& Bakin, A.A., "Experimental determination of suboptimal parameters for energyefficient control of an induction motor," International Journal of Power Electronics and Drive Systems (IJPEDS), vol. 11, no. 4, pp. 2173-2182, 2020. doi:10.11591/ijpeds.v11.i4.pp2173-2182

[16] Vladimir L. Kodkin, Alexandr S. Anikin and Alexandr A. Baldenkov, "Nonlinear Dynamics of Asynchronous Electric Drive: Engineering Interpretation and Correction Techniques," Control Theory in Engineering. IntechOpen, 2019. DOI: 10.5772/intechopen.88223

[17] Sokolovsky G.G. "Electrical drives of alternating-current with frequency controlling," ACADEMIA, pp. $267,2006$.

[18] Li, K., Luo, H., Yang, C. and Yin, S., "Subspace-aided closed-loop system identification with application to dc motor system," IEEE Transactions on Industrial Electronics, vol. 67, no. 3, pp. 2304-2313, 2019.

[19] Ahmad, M.A., Musa, Z., Suid, M.H. and Tumari, M.Z.M., "Grey wolf optimizer for identification of liquid slosh behavior using continuous-time hammerstein model," Bulletin of Electrical Engineering and Informatics (BEEI), vol. 9, no. 2, pp. 542-549, 2020. DOI: 10.11591/eei.v9i2.2074

[20] Moradifar, A., Foroud, A.A. and Fouladi, M., "Identification of multiple harmonic sources in power system containing inverter-based distribution generations using empirical mode decomposition. IET Generation," Transmission \& Distribution, vol. 13, no. 8, pp. 1401-1413, 2019. DOI: 10.1049/iet-gtd.2018.5382

[21] V.L. Kodkin, A.S. Anikin, A.A. Baldenkov, "The dynamics identification of asynchronous electric drives via frequency response," International Journal of Power Electronics and Drive Systems (IJPEDS), vol. 10, no. 1, pp. 66-73, 2019.

[22] V. L. Kodkin, A. S. Anikin and A. A. Baldenkov, "Prospects for Use of AC Drives in Industrial Robots. Identification of Quality of Asynchronous Electric Drives From Spectra of Rotor Currents," 2018 Global Smart Industry Conference (GloSIC), Chelyabinsk, pp. 1-6, 2018. doi: 10.1109/GloSIC.2018.8570111.

[23] V.L. Kodkin, A.S. Anikin, A.A. Baldenkov, "Stabilization of the stator and rotor flux linkage of the induction motor in the asynchronous electric drives with frequency regulation," International Journal of Power Electronics and Drive Systems (IJPEDS), vol. 11, no. 1, pp. 213-219, 2020. http://doi.org/10.11591/ijpeds.v11.i1.pp213-219

[24] V.L. Kodkin, A.S. Anikin, A.A. Baldenkov, "Performance identification of the asynchronous electric drives by the spectrum of rotor currents," International Journal of Power Electronics and Drive Systems (IJPEDS), vol. 10, no. 1, pp. 211-218, 2019.

[25] V.L. Kodkin, A.S. Anikin, A.A. Baldenkov, "Structural correction of nonlinear dynamics of frequency-controlled induction motor drives," International Journal of Power Electronics and Drive Systems (IJPEDS), vol. 11, no. 1, pp. 220-227, 2020. http://doi.org/10.11591/ijpeds.v11.i1.pp220-227. 